\title{
Footstep Power Generating System
}

\author{
Saranya $\mathrm{G}^{\mathrm{a}, 1}$, Manikandan $\mathrm{V}^{\mathrm{a}}$, Balaji $\mathrm{J}^{\mathrm{a}}$, Kandesh $\mathrm{M}^{\mathrm{a}}$ and Karthikeyan $\mathrm{A}^{\mathrm{a}}$ \\ ${ }^{a}$ Department of ECE, KCG College of Technology, Chennai, Tamilnadu, India
}

\begin{abstract}
The power is generated by human motion while walking on the piezoelectric sensor, which is pressed and produces kinetic energy, which is then converted into electrical energy. The generated energy is stored in the battery. The energy in the battery is used to turn on the street lights using the LDR Sensor when the sun's beam becomes dull, and to pass water to the grass using the motor with the help of the soil moisture Sensor when the soil becomes moisture. And also used for charge the mobile phones using the charging port which is installed in the park and to be used for other purposes in the park. All the data is get tracked and stored in the IOT for continuously monitoring and for future purpose.
\end{abstract}

Keywords. piezoelectric sensor, IoT, LDR sensor, soil moisture sensor.

\section{Introduction}

India is a developing country that has been ranked as Asia's second largest energy user since 2008. India's energy demand will continue to rise as the country develops, but the country's power generation capacity will be inadequate.

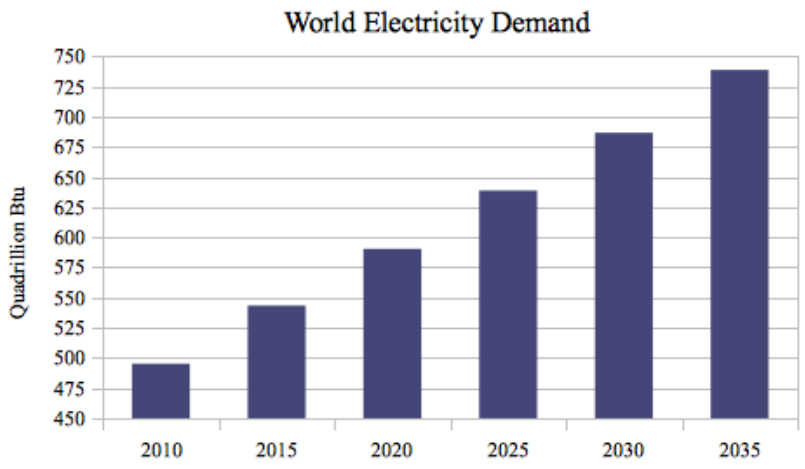

Figure 1. World Electricity Demand

Walking is the most popular human activity. Every day, humans walk for a short time, and the energy they lose by walking is tapped and converted into electrical energy. For densely populated countries like India, implementing waste energy produced by hu-

\footnotetext{
${ }^{1}$ Saranya G, Department of ECE, KCG College of Technology, Chennai, Tamilnadu.

E-mail: Saranya.ece@kcgcollege.com.
} 
man motion is critical. Many villages in India also lack access to electricity. Rather than focusing on conventional oil, we are now focusing on non-conventional energy. Conventional energy consumption is roughly equivalent to non-conventional energy usage. As a result, we will reduce waste that is detrimental to the atmosphere while still saving money. It is highly recommended because it is a one-time investment. In this project, we primarily aim to capture power produced by human motion using a piezoelectric sensor, then move the power to a battery, which then applies the power to street lights and motors. As a result, the footstep power generating system would aid in the development of the nation's economy.

\section{Related Study}

Sensor enabled Internet of Things for smart cities [1,2] reflects the fact that the world's population is increasingly increasing, putting pressure on cities. As a result, many government and private sector organisations are working to identify long-term solutions to these complex issues. In the last few years, IoT has drawn never-before-seen interest. In this paper, we look at the concepts of sensor-enabled Internet of Things, which links billions of sensors, and discuss their potential in the construction of smart cities. The main goal of this paper is to correct the flaw and review the current system's latest trends in order to recognise some of the major issues with sensor-enabled IoT. The author of [3] provided an overview of China's IoT growth, including policies, R\&D plans, applications, and Standardisation. This paper is written from China's Points of view, To address the architecture challenge, the report portrays certain challenges in terms of technology, applications, and Standardisation, as well as proposing an open and general IoT architecture comprised of three platforms [3]. The main goal of [4] is to create a renewable electric energy source that can be used to charge a cell phone. This paper was generated in order to generate renewable electricity and reduce energy waste. A greater number of pedestrians use the subway, stairs, and highways, causing vibrations under the floors. IoT connected to piezoelectric material monitors energy generation and is linked to a multicontrol device for wireless network communication with a computer or cell phone. The system proposed by [5] describes the electrical energy is generated by walking in treadmill which is rotating in the circular motion the electricity is produced and that energy is stored in the battery and used for future purpose.

This system by [6] described the mechanical energy is converted into electrical energy by using the piezo electric sensor and then it is stored in the battery. RFID is the sensor used for phone charging purpose. RFID card is used to charge the mobile phones. The prototype design and testing of a hybrid power management system for a wireless sensor mote is designed by [7]. The sensor mote, which is installed on the outside of a high voltage transformer, generates electricity from the transformer tank vibration using a piezoelectric cantilever. The authors of [8] proposed a decision-making procedure to assist a city energy manager in evaluating the most cost-effective energy retrofit plan for an existing public street lighting system across a large metropolitan area. The proposed decision model aims to maximise energy consumption reduction while also achieving an optimal allocation of retrofit actions among street lighting subsystems, all while making efficient use of the available budget. A quadratic knapsack problem is used to express the resulting optimization problem. 


\section{Existing System}

In the current scheme, human labour is needed to maintain park zones for watering purposes. We will deal with new techniques in order to provide an effective and automated process.

\section{Block Diagram}

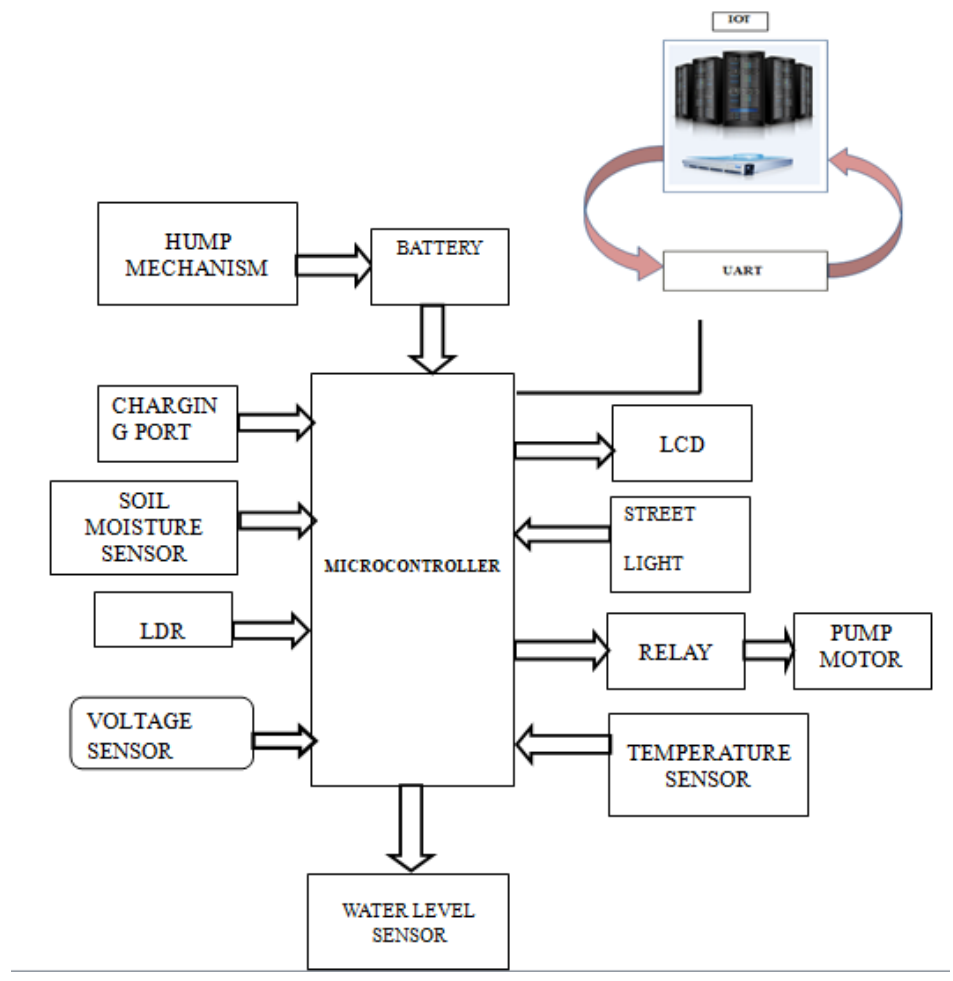

Figure 2. Block Diagram for Footstep Power Generating System

In Block diagram, Electrical energy is produced by people walking over the ground surface. Using a special arrangement known as a Hump Mechanism (Figure 3), this electrical energy can be used to generate electricity. By allowing the people to walk over the piezo electric sensor it undergone some of pressure and here the kinetic energy is converted into electrical energy by the way the electrical energy is stored to the battery. The energy produced is stored in a battery and used in a variety of ways using Arm Microcontroller which is shown in the Figure 2. We also use the Internet of Things (IoT) to constantly track soil moisture in park zones. We can power the pump motor automatically via IOT and for watering purposes in the park zones with the water supply present within the parks whenever the soil moisture is dry.

The electricity that is used is often used to switch on street lights. Just when the sun's rays become dull are the street lights switched on. This improves battery life and 


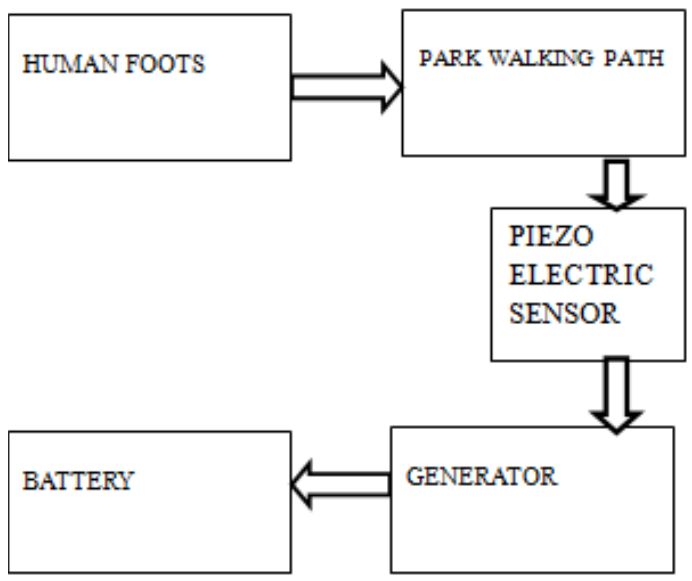

Figure 3. Block diagram for Hump Mechanism

the efficient use of renewable energy. IOT is constantly track temperature in the park and the temperature degree is stored in IOT server. We can also charge our Mobile phones through charging port which is in the park. Those who haven't have charge in their mobile during emergency situation, they can charge their phones in the park. The water source in the park can be monitored using a water level sensor. The information from the various sensors is shown on the LCD and saved on the web server.

\section{Result and Analysis}

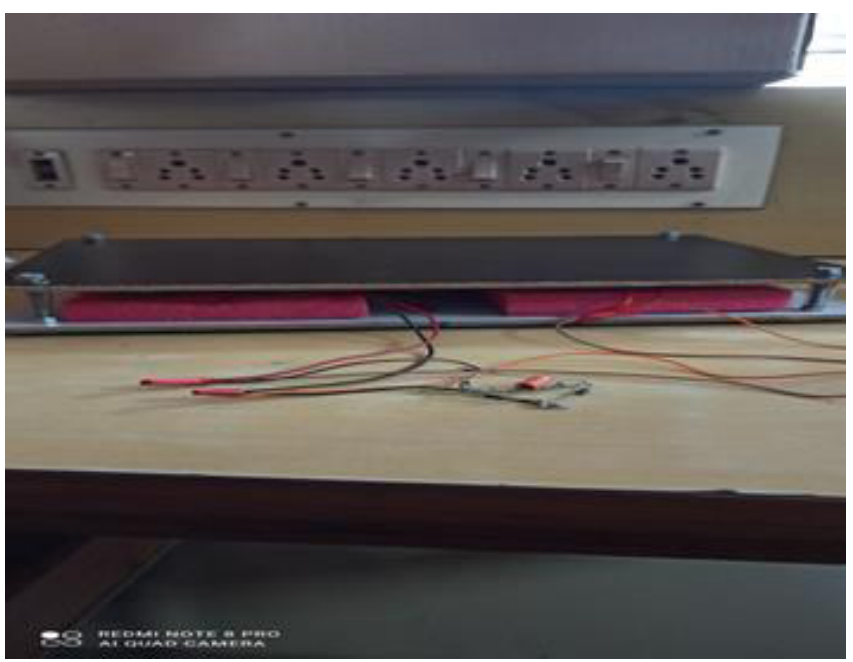

Figure 4. Hump Mechanism

We used a 22 Piezoelectric sensor in 1 Square ft. 


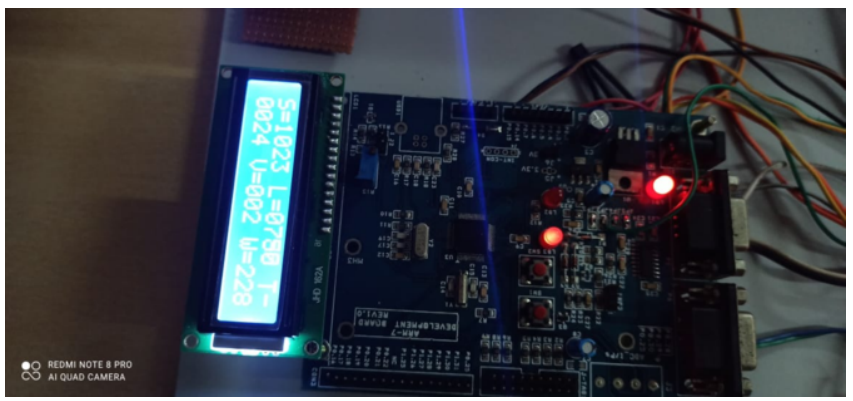

Figure 5. Sensors Values

As Piezoelectric Sensors power generating varies with different steps, we obtain

Minimum voltage $=1 \mathrm{~V}$ per step

Maximum voltage $=5.2 \mathrm{~V}$ per step

We took an average of $50 \mathrm{~kg}$ weight pressure from a single person

Considering the steps of a $50 \mathrm{~kg}$ weighted single person, the average calculation is:

It takes 800 steps to increase the battery's $1 \mathrm{~V}$ charge. So, total steps required to increase $12 \mathrm{~V}$ in battery is,

$$
\begin{aligned}
& =(22 * 800) \\
& =17600 \text { steps }
\end{aligned}
$$

We took an average of two steps in one second because we will be implementing our project in a populated area where footstep as a source will be available. Time required for 17600 steps is,

$$
\begin{aligned}
& =17600 /(60 * 2) \\
& =17600 / 120 \\
& =146.6 \text { minutes (Approximately) }
\end{aligned}
$$

\section{Conclusion and Future Works}

We overcome the flaws in the current system with the footstep power generation system presented in this project, and every phase is automated, reducing man-made interference. We successfully implemented a new park automation model based on renewable energy. In the future, we can improve our project by installing piezoelectric sensors in public areas like streets, while people walking on the street and energy is generated. With this energy, we can turn on street lights that are useful to the public. In addition, by placing this piezoelectric sensor in tiles placed throughout the house, electric energy is produced every time someone steps on the tiles. We can use this energy for a variety of purposes, such as turning on a fan or lights etc.

\section{References}

[1] Sumi L, Ranga V. Sensor enabled Internet of Things for smart cities. In2016 fourth international conference on parallel, distributed and grid computing (PDGC) 2016 Dec 22 (pp. 295-300). IEEE.

[2] Li Z. Mountain environment detection and power transformer fault diagnosis based on edge computing. Arabian Journal of Geosciences. 2021 Jun;14(11):1-3. 
[3] Chen S, Xu H, Liu D, Hu B, Wang H. A vision of IoT: Applications, challenges, and opportunities with china perspective. IEEE Internet of Things journal. 2014 Jul 9;1(4):349-59.

[4] Ambrish R, Ashwini S, Dharun Surya MK, Karthick M, Kalaikumar T. Piezoelectric Based Automatic Generation Using IOT. In2019 Second International confrence on Nextgen Technologies. 2019 Mar (pp. 179-185).

[5] Gopinath R, Lavanya M, Arivalagan M. Power Generating using Human Foot Step With Piezo Electric Sensor and Treadmill. International Journal of Pure and Applied Mathematics. 2018;119(16):3171-82.

[6] Shradha P, Pratik B, Hemant C. "Advanced Foot Step Power Generation System using RFID for Charging”. International Research Journal of Engineering and Technology. 2020 Feb;07(02):2408-12.

[7] de Villiers DJ, Kaplan S, Wilkinson RH. Energy harvesting for a condition monitoring mote. In 2008 34th Annual Conference of IEEE Industrial Electronics 2008 Nov 10 (pp. 2161-2166). IEEE.

[8] Carli R, Dotoli M. A dynamic programming approach for the decentralized control of energy retrofit in large-scale street lighting systems. IEEE Transactions on Automation Science and Engineering. 2020 Feb 21;17(3):1140-57. 